\title{
MODIFICATION OF THE X-RAY DIFFRACTION EFFICIENCY OF LITHIUM FLUORIDE CRYSTALS BY SURFÄCE TREATMENT
}

Barton 0. Sell1ck

July 22, 1976

Prepared for U.S. Energy Research \& Development

Administration under contract No. W-7405-Eng-48

\section{㢟}

LAWRENCE

LVERMOAE LABORATORY

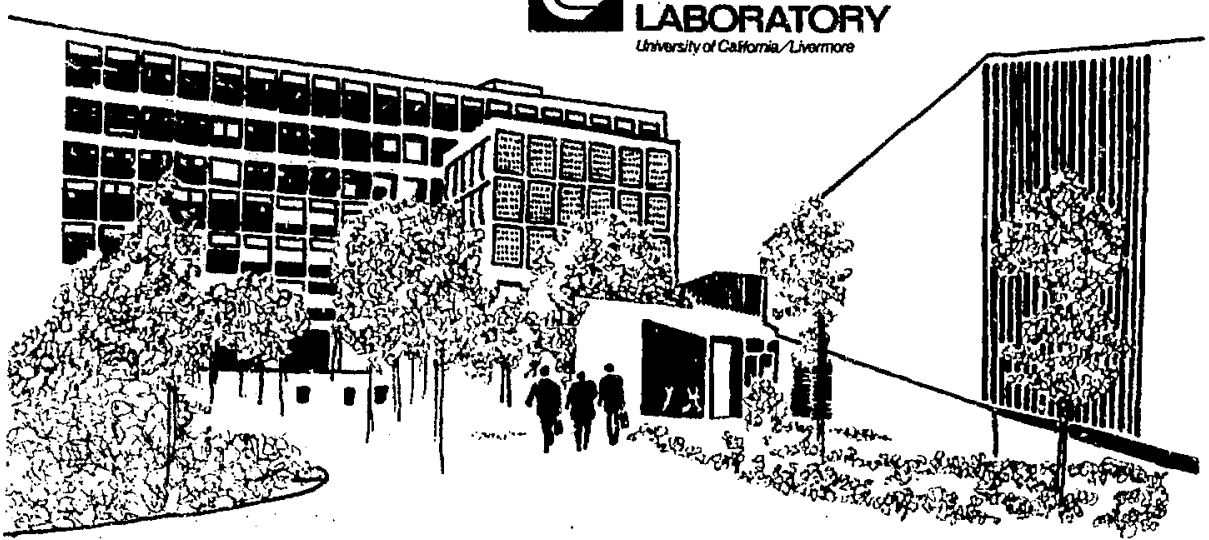




\section{NOTICE}

"This report was preparet as an account of work eponsored by the United States Government. Weither the United States nor the United Stater Enersy Reseatch \& Devclnpment Adminlsteation, nor any of their employess, nor any of their coniractort, subcontractors, or theit employess, makes any warranty, express or implied, or otsumes any lesal liability or reapunsibility for the mecuracy, compleieness of usefulness of eny information, appuratus, ponduct or process discloned, or steresents that its use would not infringe privately-owr:ed tights."

Printed in the United States of America Available from

National Technical Information Service

U.S. Department of Commerce

5285 Port Royal Road

Springfield, VA 22161

Price: Printed Copy $\$$; Microfiche 52.25

\begin{tabular}{|c|c|c|c|}
\hline Pre Rans: & $\begin{array}{c}\text { Domestic } \\
\text { Price }\end{array}$ & Pow Range & $\begin{array}{c}\text { Domentic } \\
\text { Prioe }\end{array}$ \\
\hline $001-025$ & S 3.50 & $326-350$ & 10.00 \\
\hline $026-050$ & 4.00 & $351-375$ & 10,50 \\
\hline $.051-075$ & 4.50 & $376-400$ & 10.75 \\
\hline $076-100$ & 5.00 & $401-425$ & 11.00 \\
\hline $101-125$ & 5.25 & $426-450$ & 11.75 \\
\hline $126-150$ & 5.50 & $451-475$ & 12.00 \\
\hline $151-175$ & 6.00 & $476-500$ & 12.50 \\
\hline $176-200$ & 7.50 & $501-525$ & 12.75 \\
\hline $201-225$ & 7.75 & $526-550$ & 13.00 \\
\hline $226-250$ & 8.00 & $551-575$ & 13.50 \\
\hline $251-275$ & 9.00 & $576-600$ & 13.75 \\
\hline $276-300$ & 9.25 & $601-u p$ & $\bullet$ \\
\hline $301-325$ & 9.75 & & \\
\hline
\end{tabular}

Add \$2.50 for each saditional 100 page Increinent from 601 to 1,000 pages: add $\$ 4.50$ for each additional 100 page increment over 1,000 pager. 


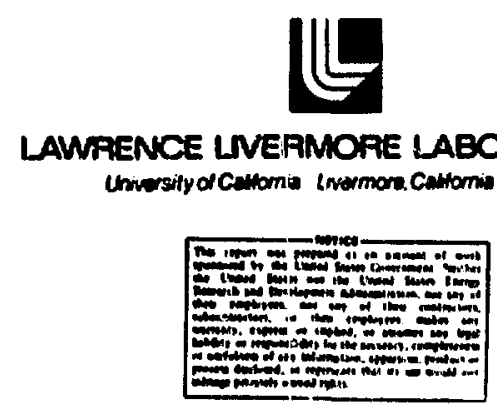

I:CRL- 520Bi

\title{
MODIFICATION OF THE X-RAY DIFFRACTION EFFICIENCY OF LITHIUM FLUORIDE CRYSTALS BY SURFACE TREATMENT
}

\author{
Barton 0 . Sellick
}

IS. date: July 22, 1976

or $\underline{W-1 / 405-E N k+48}$ 


\title{
MODIFICATION OF THE X-RAY DIFFRACTION EFFICIENCY OF I.ITHICM FLLLORIDE CRYSTALS BY SLRFACE. TREATMENT
}

\begin{abstract}
Absitract
Convex-curved crystals of Ifthlum fluorlde demonstralt poud disperslen and elf folctary whon used in reflection for $x$-ray spectrat

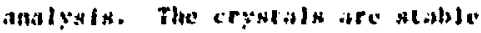
and reasonably unafiocted by harsh covel rongerita. In idditidom, they are mecitanically st runt. saindly cloatable

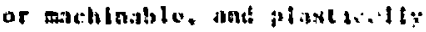
defortable with heide ta the prosest stwat itst

crystal walders here lefe efeler ilear an cleaved or tere subjerted to

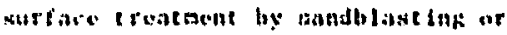

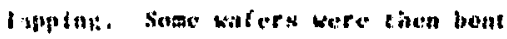

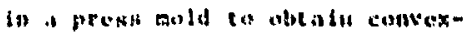
curvod regestats of differling radil.

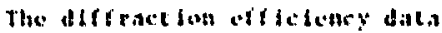
prosented staw how murfiace createant

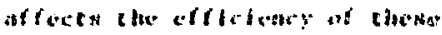

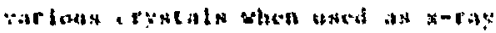
ditstactims arents.
\end{abstract}

\section{Introduction}

stace reyetats have came lato

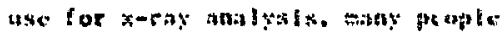

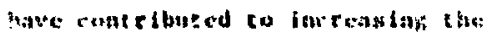
ef Icleacy and resolut ina of wuels crystals. Oar incifentict use af lishlue luorido orytatik uver bles

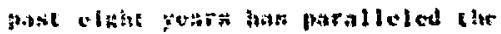

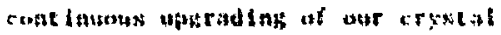

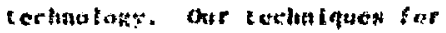

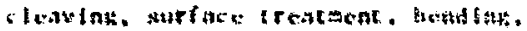

ctrolang ansd ovaluat fon or stat

ringked eryent are treatlod ba roeche respara,

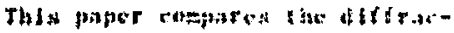

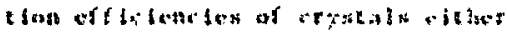

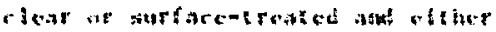

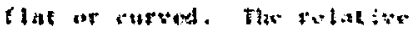

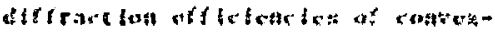

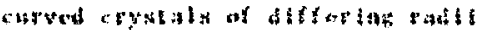
Ag' al was shombl. 


\section{Esperimental Methods}

Wafers cleaved from a lithium fluoride boule, $38 \times 38 \times 0.7 \mathrm{~mm}$ in thickness, were evaluated on a spectrogoniometer for " $d$ " spacing and diffraction efficiency of the copper ka energy. The results of surface treatment were assessed using a 10-channel, x-ray fluorescence spectrometer using wavelength dispersive analyais ( 6 to $60 \mathrm{keV}$, 1.e., 1.9 to $0.22 \AA$ ). All the techniques and procedures employed were detalled and illustrated in a prevlous report. 1
Dif $f$ raction ef fictency ( $E$ ) is calculated according to the following simpl if ied formula ${ }^{l}$

$E=\frac{I_{d}-\text { (background pinhole area) }}{I_{0}-\text { background }} \cdot \frac{d}{D}$

$I_{d}=I_{d i f f r a c t e d}$

$I_{0}=I_{\text {maIn beam }}$

d/D - Geometry correction factor

Pinhole area $=$ zero-crder pinhole correction

\section{Experimental Results}

Compartsons were made of the diffraction efficiencies of individual flat wafers, as cleaved, without surface sreatment. As can be seen in F18. 1, differences are evident even between $11 k e-o r$ lented and adjacent wafers from the same boule.

A* shown In FIg. 2, we compared the diffraction efficiencies of flat ve convex-curved crystals and uncreated vo surface-treated crystals. With respect to flat crystals, the diffraction efficlency increases six 10 eight times af ter surface treatment (compare $A$ and $B$ ). Generally, the sandblasted crystal (\$1 grit, 30 s/side) Is supertor to the lapped crystal (600 grit aluminum oxide, $2 \mathrm{~min} / \mathrm{side}$ ) both in efficiency and in the ease and speed of the method.

On the other hand, prior surface treatment of the convex-curved crystal. does little to enhance its ef fictency as a x-ray dispersing monochromator. That is, If a flat, surface-treated crystal ( $\Lambda$ ) of Fig. 2 Is heated to $475 \% 575^{\circ} \mathrm{C}$ and rolled ${ }^{3}$ or pressed in a mold to a convex-curved crystal of a desired radius (C), Its efficiency as an $x$-ray diffracting agent generally is found to be less than for a $f$ lat, untreated crystaj (B). Enhancement of the diffraction efficiency that occurred aćter 


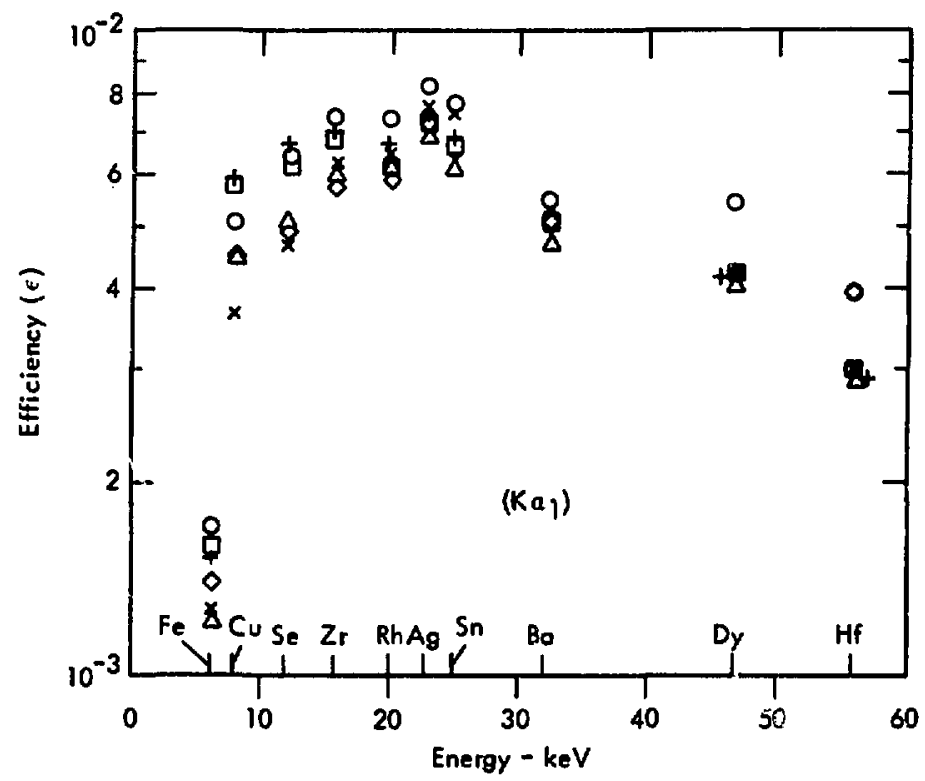

Fig. 1. Diffraction efficiencies of seven randomly-selected, tlat lithiun: Iuoride wafers, as cleaved and without surface treatment. Each symbol represents an individual crystal.

surface treatment of the flat crystal is essentially nullifled when the crystal is bent.

with respect to using flat crystals as $x$-ray dispersing agents, the critical points for or against surface treatment would be the resu'ting resolution and IIne width on the one hand and the intensity on the wher. Obviously, if a curved crystal is to be used as an analyzer, prior surface treatment is of little value.

Figure 3 compares the ef $i$ ciencles of convex-curved crystals of different radil (3,6 and $25 \mathrm{~mm}$ ). For crystals of each dimension, hoth the $k a_{1}$ and $k \beta_{1}$ curves are shown as well as the plot of main beam intensity ( $I_{0}$ ). As the crystal radfus becomes smalier, there is less crystal material avallable to satisfy 


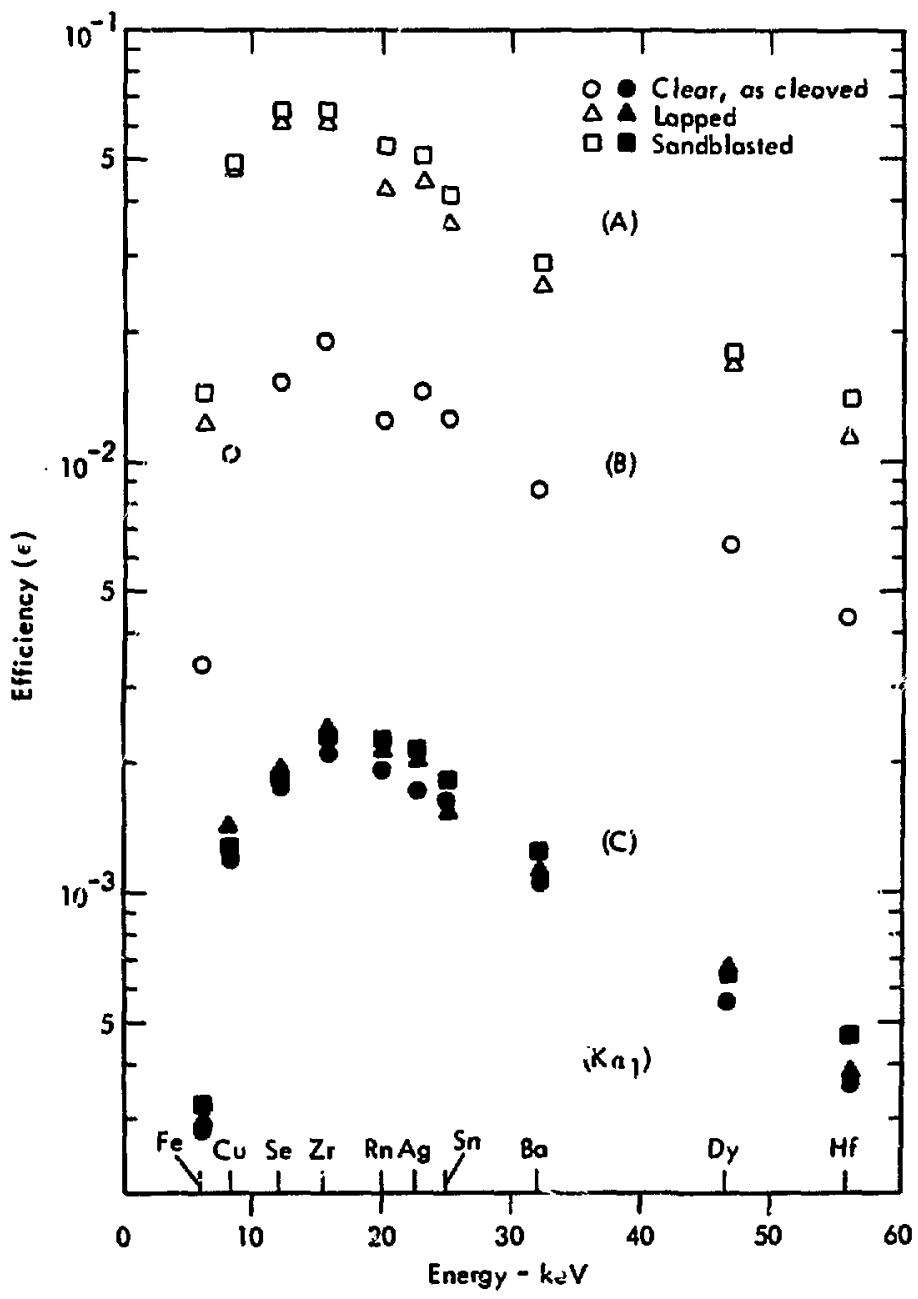

Fig. 2. Diffractior. efficiencies of flat vs convex-curved crystals ( $r=25$ ma?. (A) Flat crystals, surface treated, (B) Flat crystals, clear and untreated, (C) curved crystals, treated and untrented. Flat crystals are designated by open symbols, curved crystals by solfd sylibols. 


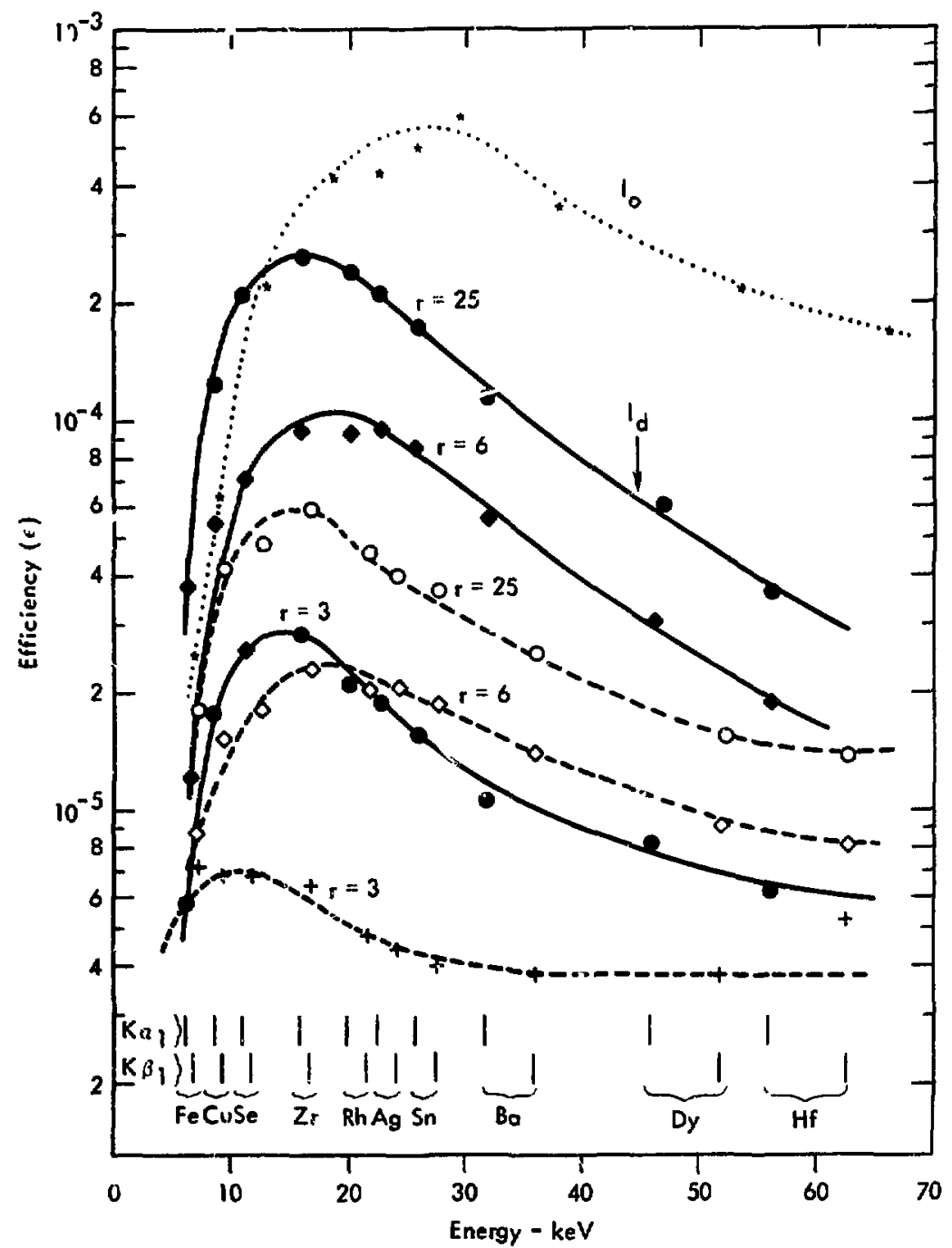

Fig. 3. Diffraction efficiencies of convex-curved lithium fluoride crystals (200) having different radii $(3,6$ and $25 \mathrm{~mm})$. The separate $\mathrm{Ka}$, (solid line) and $K \beta_{1}$ (dashed line) curves are shown for each rausius. 
the Bragg angle. Therefore, the overall diffraction efficiency is reduced.

Plastic defothation of ithium fluorlde wafers $(0.2$ to $2.0 \mathrm{~mm}$ thick) to curved crystals with radil of 2 to $10 \mathrm{en}$ san be read $11 y$ accomplished by either rolling ${ }^{3}$ or pressing. Pressing gives a more unifortn radius and generally better crystals are obtained. The pressing procedure was used in all of the present work.

Rolling of the hot crystal results in a variable radius because clamping leaves a flat end and a tendency to warp and to spring back. Diffraction intensity variations, causing a "woodgrain" effect in fllmed opectra, seem more prevalent in rolled than in pressed crystals. Therm 1 shock may cause crystal breakage unless great palus are taken to preheat the crystal and to provide even cooling upon its removal from the rolling tool. When successive crystals are being bent, the rolling method $f:$; much slower than the press mold procedure because it is more difficult and time-consuming to climp the pre-heated crystit in the hot rolling tool.

When the crystal is slipped into the press mold, self-centering is automat $1 \mathrm{c}$. When the press mold comes to temperature in the oven, the mold is closed mumentarily. Upon reopening, the hot crystal is remnved with preheated tongs and let cool at room temperature on a hot carbon block.

\section{Acknowledgments}

This work ciuld not have been accomplished without the efforts of T. A. Boster - or physics and crystallographic advice; R. Buddingh,
M. Spann, and T. Valk for elecironics design, fabrication, and Installation; and R. Burleigh and R. Columbo for mechanical design and fabrication.

\section{References}

1. B. 0. Sellick, Lawrence Livermore Laboratory Rept. UCRL-52086 (1976).

2. L: S. Birks and R. T, Seal, J. Appl. Phys. 28, 541 (1957).

3. L. S. Birks, Rev. Sc1. Instrum. 41, 1129 (1970). 